
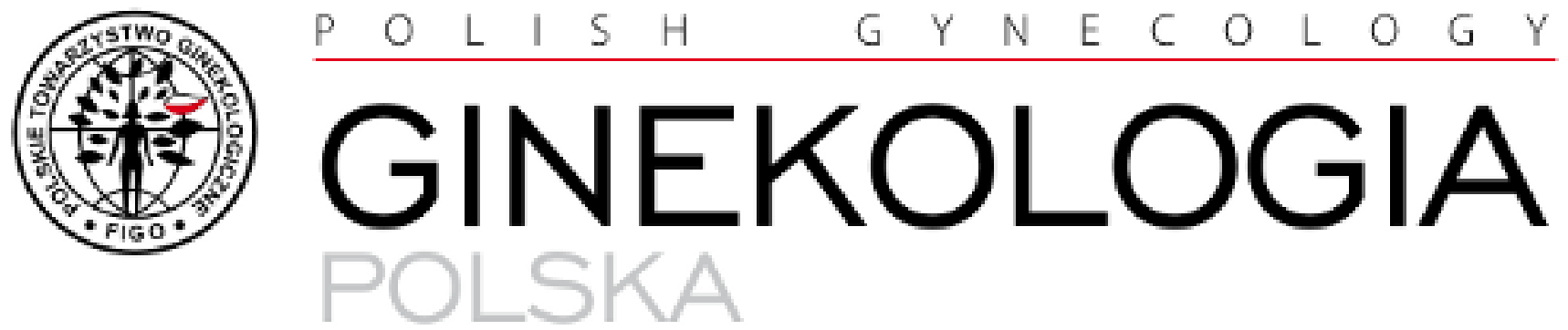

ORGAN POLSKIEGO TOWAAZYSTWA GINEKOLOGICZNEGO

THE OFFICIAL JOURNAL OF THE POLISH GYNECOLOGICAL SOCIETY

ISSN: 0017-0011

e-ISSN: $2543-6767$

\title{
Adverse pregnancy outcomes for women with endometriosis: a systematic review and meta-analysis
}

Authors: Jian-qing Wang, Jia-miao Zhang, Bin Qian

DOI: 10.5603/GP.a2021.0081

Article type: Research paper

Submitted: $2020-12-15$

Accepted: $2021-03-11$

Published online: 2021-08-03

This article has been peer reviewed and published immediately upon acceptance.

It is an open access article, which means that it can be downloaded, printed, and distributed freely, provided the work is properly cited.

Articles in "Ginekologia Polska" are listed in PubMed. 


\section{ORIGINAL PAPER/OBSTETRICS}

Adverse pregnancy outcomes for women with endometriosis: a systematic review and meta-analysis

Running title: Adverse pregnancy and endometriosis

\section{Jian-qing Wang ${ }^{1}$, Jia-miao Zhang ${ }^{2}$, Bin Qian'}

${ }^{1}$ Department of Obstetrics and Gynecology, Yancheng Clinical College of Xuzhou Medical University, The First people's Hospital of Yancheng, Yancheng, China ${ }^{2}$ Department of Anesthesiology, Yancheng Clinical College of Xuzhou Medical University, The First people's Hospital of Yancheng, Yancheng, China

\section{Corresponding author:}

\section{Bin Qian}

Department of Obstetrics and Gynecology, Yancheng Clinical College of Xuzhou Medical University, The First people's Hospital of Yancheng

No.66, Renmin South Road, Yancheng, Jiangsu 320900, China

e-mail: qianbin2020_yc@163.com

\section{ABSTRACT}

Objectives: This study aimed at assessing the adverse outcomes of pregnancy in women with endometriosis.

Material and methods: The Cochrane, Embase and PubMed databases were searched for identifying the required studies published before June 2019. Meta-analyses of relative risk (RR) were performed under the random-effects model to estimate the risk of selected adverse outcomes of pregnancy in females with endometriosis.

Results: Twenty-eight studies (53,141 women with and 2,355,923 women without endometriosis data) were selected for meta-analysis. Endometriosis bearing females had a significantly higher risk placenta previa (RR 3.92 [95\% CI 2.48-6.20]), miscarriage (RR 1.31 
[95\% CI 1.06-1.61), gestational hypertension (RR 1.30 [95\% CI 1.02-1.65]), cesarean section (RR 1.48 [95\% CI 1.33-1.65]) and preeclampsia (RR 1.18 [95\% CI 1.09-1.28]). The incidence of placental abruption was not statistically significant between the groups (RR 3.62 [95\% CI [0.99-13.28]).

Conclusions: Women suffering from endometriosis are at higher risks of miscarriage, preterm birth, gestational hypertension, placenta previa, cesarean section, and preeclampsia. Key words: endometriosis; meta-analysis; pregnancy outcome 


\section{INTRODUCTION}

Endometriosis, a chronic benign proliferative condition, is the result of the ectopic growth of living endometrial tissue with stroma and glands outside the uterus [1]. Major symptoms of endometriosis are dysmenorrhea, infertility, sexual discomfort, and abnormal menstruation [2]. Approximately 20-25\% of women with endometriosis remain asymptomatic [3]. It has been reported that the incidence of endometriosis is $10 \%$ to $40 \%$ in women with pelvic pain or a history of infertility $[4,5]$. In Germany, the standardized incidence and prevalence rates of endometriosis are reported to be 3.5 and 8.1 per 1000 women, respectively [6]. However, the incidence in women between the age of 35 and 44 years was 12.8 per 1000 women [6]. Diagnosis of endometriosis is often delayed (average delay is 6.7 years). Earlier referral and diagnosis can help in controlling pain and pathology and in preserving fertility. High cost of diagnosis, treatment and overlapping symptoms e.g., cyclic or acyclic pain are among notable delaying factors [7].

Endometriosis pathophysiology is still misunderstood. Menstrual blood regurgitation, Mullerian duct abnormalities and coelomic epithelial metaplasia are among notable theories. Historically, retrograde menstruation (menstrual blood with living cells backflow towards the peritoneum via the fallopian tubes) and the implantation of endometrial tissue in the peritoneum were identified as the etiological features of endometriosis [8]. Later research showed that inflammatory processes such as the over secretion of inflammatory cytokines and chemokine and other mediators such as prostaglandins and metalloproteinases play a vital role in the pathodynamics and pathogenesis of endometriosis [9]. Such pathogenetic processes are supported by the presence of free radicals and reactive oxygen entities which promote the processes leading to symptomatic intensity and infertility [10]. The most common symptoms of endometriosis include irregular menstruation, dysmenorrhea, chronic pelvic pain, infertility, and dyspareunia. These often affect psychological and social wellbeing of patients which makes endometriosis a debilitating condition that compromises the sexuality and social relationships, as well as mental health [11, 12]. 


\section{Objectives}

Numerous research publications have indicated a link between endometriosis and consequent complications in pregnancy. Our goal was to identify studies which reported the adverse outcomes of pregnancy in women with endometriosis and perform a meta-analysis of statistical indices to attain up to date evidence on the link between endometriosis and pregnancy complications.

\section{MATERIAL AND METHODS}

\section{Search strategy}

Pubmed, Embase and Cochrane databases were consulted for research articles related to the influence of endometriosis on adverse pregnancy outcomes published in the English language. We also screened the reference lists of related articles and if the literature search was finished by June 2019. Two independent investigators performed the literature search. An additional investigator was involved if any disagreements arose.

Primary search terms were 'endometriosis-pregnancy-adverse outcomes'. This phrase was used in combination (conjunctions: “AND” or “OR”) with several other keywords in secondary searches including preterm birth, placenta previa, miscarriage, gestational hypertension, caesarean section, preeclampsia, placental abruption, adenomyosis, fertility, obstetric, assisted reproduction technology, ART, in vitro fertilization, IVF, and spontaneous.

All publications were independently assessed by two reviewers to establish if they met the inclusion and exclusion criteria. A third reviewer decided any discrepancies.

\section{Inclusion and exclusion criteria}

In following the principles of PICOS (Participants, Interventions, Comparisons, Outcomes and Study design), the inclusion criteria were patients, women suffering from endometriosis in the exposed group, while the control group included healthy women; Intervention, with and without ART pregnancies; Comparison, Adverse pregnancy outcomes between endometriosis and control groups; Outcomes of interest, Adverse pregnancy 
outcomes; Studies, Cohort studies. Exclusions were the studies without a control group, lacking numerical data, reporting only post-parturition outcomes, or describing a case only.

\section{Extraction of data and quality assessment}

The data were obtained from selected publications as basic information which include the country, author name, year of publication, interventions of the exposed and control groups, age, sample size, and pregnancy method. Also included were the clinical outcomes including preterm birth, miscarriage, placenta previa, cesarean section, gestational hypertension, preeclampsia, and placental abruption. The quality of the performed studies was investigated by using the Jadad checklist. Two independent reviewers performed the data extraction and assessed the quality of the studies. Disagreements were solved through dialogue between these two reviewers or by involving a third reviewer.

\section{Statistical analysis}

The statistical heterogeneity of the data of the clinical trials was assessed using the Chisquared and $\mathrm{I}^{2}$ tests. The publication bias was examined using Egger's test funnel plot, as well as the Begg's and Mazumdar's rank test. Meta-analyses of relative risk (RR) for preterm birth, miscarriage, placenta previa, caesarean section, gestational hypertension, preeclampsia, and placental abruption were performed under the random-effects model using the dichotomous data reported by the individual studies. According to the pregnancy method, we used subgroups as: a) ART (both exposed and control groups were treated by ART), b) spontaneous or ART (SART; both groups had either spontaneous or ART pregnancies), c) natural pregnancy (NP; both groups had natural pregnancies), unclear (UC; the articles did not provide information to differentiate pregnancy type). All the analyses were carried out with Stata software (version 10; Stata Corporation, TX, USA).

\section{RESULTS}

\section{Study characteristics}


A total of 1,679 publications were found during the literature search. Excluded were 1,572 articles after title or abstract screening. A review of 107 research articles led to exclusion of 79 articles based on failure to fulfil inclusion criteria. Finally, 28 cohort studies were selected for meta-analysis including 53,141 women in the exposed group and 2,355,923 women in the control group [13-39]. The process of screening and selection of the study is presented in Figure 1. The main features of the study are given in Table 1.

The funnel plot for log RR in the risk of preterm birth was markedly symmetrical, signifying a lack of bias (Fig. S1). No significant funnel plot asymmetry was identified by Begg's and Mazumdar's rank test $(Z=0.20, p=0.844)$ or the Egger's test $(p=0.438)$.

\section{Preterm birth}

Twenty studies with 23,072 women in the exposed and 2,226,870 in the control groups reported the risk of preterm birth. Endometriosis-affected women showed significantly higher incidence of preterm birth (RR 1.59 [95\% CI 1.35-1.87]; Fig. 2). In subgroup analyses, the prevalence of preterm birth was significantly higher in spontaneous or ART (RR 1.78 [95\% CI 1.29-2.45]), NP (RR 1.62 [95\% CI 1.30-2.02]), and UC (RR 1.40 [95\% CI 1.03-1.90]) subgroups.

\section{Miscarriage}

Nine studies with 33935 women in the exposed and 127,224 in the control groups reported the risk of miscarriage. Endometriosis considerably enhanced the risk of miscarriage (RR 1.31 [95\% CI 1.06-1.61]; Fig. 3). The miscarriage risk was significantly higher in ART (RR 1.12 [95\% CI 1.01-1.25]) and UC (RR 1.93 [95\% CI 1.47-2.25]) subgroups.

\section{Placenta previa}

Twelve studies with 6,258 women in the exposed and 96,214 in the control groups reported the risk of placenta previa. Compared to the control group, endometriosis group had a considerably larger risk of placenta previa (RR 3.92 [95\% CI 2.48-6.20]; Fig. 4). The 
placenta previa risk was significantly higher in ART (RR 3.12 [95\% CI 1.06-9.21]), SART (RR 4.87 [95\% CI 2.46-9.63]), and NP (RR 4.33 [95\% CI = 1.25-15.02]) subgroups.

\section{Caesarean section}

Sixteen studies with 21,901 women in the exposed and 216, 8884 in the control groups reported the risk of caesarean section. Endometriosis increased the risk of caesarean section significantly (RR 1.48 [95\% CI 1.33-1.65]; Fig. S2). The risk of caesarean section was significantly higher in ART (RR 1.45 [95\% CI 1.15-1.82]), SART (RR 1.46 [95\% CI 1.221.75]), NP (RR 1.86 [95\% CI 1.13-3.06]), and UC (RR = 1.33, 95\% CI = 1.07-1.65) subgroups.

\section{Gestational hypertension}

Eleven studies with 7,119 women in the exposed and 636,681 in the controlled groups reported the prevalence of gestational hypertension. Endometriosis was linked to a significantly enhanced risk of gestational hypertension (RR 1.30 [95\% CI 1.02-1.65]; Fig. S3). A significantly higher gestational hypertension risk was observed in ART ( $R R=1.78$, 95\% CI = 1.43-2.23) subgroup.

\section{Preeclampsia}

Eleven studies with 16,901 women in the exposed and 1,579,453 in the controlled groups reported the risk of preeclampsia. Endometriosis remarkably enhanced the risk of preeclampsia (RR 1.18 [95\% CI 1.09-1.28]; Fig. S4). The preeclampsia risk was significant higher in ART (RR 1.16 [95\% CI 1.06-1.27]), and SART (RR 1.25 [95\% CI 1.03-1.53]) subgroups.

\section{Placental abruption}

Ten studies with 5,615 women in the exposed and 86,907 in the controlled groups reported the risk of placental abruption. No significant difference was observed in the risk of 
placental abruption between women with and without endometriosis (RR 3.62 [95\% CI 0.9913.28]; Fig. S5). However, the incidence of placental abruption was significantly higher in SART (RR 10.94 [95\% CI 1.17-102.38]) subgroup.

\section{DISCUSSION}

The meta-analysis performed for 28 studies has successfully identified the presence of endometriosis in women increases the risk of placenta previa, preterm birth, miscarriage, gestational hypertension, caesarean section, and preeclampsia. In ART subgroup, the incidence of preterm birth, miscarriage, caesarean section, placenta previa, caesarean section, gestational hypertension, and preeclampsia was higher in endometriosis affected women, whereas in NP subgroup, the incidence of placenta previa, preterm birth, and caesarean section was significant higher in women with endometriosis. Higher statistical heterogeneity in the meta-analyses is an important concern which creates a need for further studies and the availability of more homogeneous data for refining the evidence gathered herein.

In a recently published meta-analysis, in comparison with endometriosis women, women with endometriosis exhibited enhanced odds of gestational hypertension, pre-eclampsia and/or pre-eclampsia, gestational cholestasis and diabetes, antepartum hemorrhage, placenta previa, vantepartum hospital admissions, malpresentation, labor dystocia, caesarean section. Fetal preterm premature rupture of membranes, preterm birth, small for gestational age $<10^{\text {th }}$ \%, NICU admission, stillbirth and neonatal death [40].

In a similar report, compared with heathy controls, women with endometriosis had a significantly greater chance of miscarriage (odds ratio (OR) 1.75 [95\% CI 1.29-2.37], preterm birth (OR 1.63 [95\% CI 1.32-2.01]), caesarean delivery (OR 1.57 [95\% CI [1.391.78]), small size for gestational stage (OR 1.27 [95\% CI 1.03-1.57]) and placenta previa (OR 3.03 [95\% CI 1.50-6.13]). The incidence of preeclampsia and gestational hypertension had no significant difference between the women of control and endometriosis group [41]. These findings are consistent with our results in general. However, the conclusions regarding gestational hypertension and preeclampsia are inconsistent. The risks of gestational 
hypertension and preeclampsia in the eligible studies were also inconsistent suggesting that future studies with larger sized and better design of studies are required to authenticate these findings. Recently, in a population-based longitudinal study in Taiwan with 6300 women, a prior diagnosis of endometriosis was found to be an independent risk factor for the incidence of gestational hypertension or preeclampsia [42]. On the other hand, a recent meta-analysis has reported that endometriosis does not pose a significant risk of preeclampsia or its more severe forms in either natural or ART pregnancies [43].

We have also found the incidence of placental abruption to be insignificantly different between women of control and endometriosis group. A meta-analysis of five case-controlled studies has also found no differences in the incidence of placental abruption (OR 0.44 (95\% CI 0.10 - 1.87) between women with and without endometriosis [44].

Endometrium is a healthy tissue that resides in the uterine cavity. When endometrium is found growing outside the uterus, a diagnosis of endometriosis is given. Patients with endometriosis typically have difficulty forming luteinium and have abnormalities in ovulation due to dysfunction of the ovaries. Transport of fertilized eggs in patients with moderate to severe disease is easily disturbed by adhesion between the ovaries and fallopian tubes, resulting in infertility. However, the treatment of endometriosis may also have an effect later in the reproductive cycle.

Although ovarian endometriomas and peritoneal superficial lesions represent the majority of implanted endometriosis within the pelvis, the most challenging conditions are extra pelvic endometriosis and deep infiltrating endometriosis. Occasionally signs and symptoms are reduced by using medical therapy [45]. However, in various patients, a complete eradication with nerve-sparing and vascular sparing approach [46, 47] is desired to restore anatomy and function of normal pelvic.

Among the strengths of the present study, to the quantification of the endometriosis effect on pregnancy outcomes in as a pooled effect size of large sample, use of specified inclusion and exclusion criteria, use of precise statistical measures for seeking risk indices, and the inclusion of studies with considerably larger population sizes are notable points. There were 
however some limitations that should be noted. These include: 1) only cohort studies were used for the analyses; 2) Many studies had some limitations to fulfil the inclusion and exclusion criteria; 3) use of a variety of reproduction techniques in included studies might had contributed to the statistical heterogeneity observed in the meta-analyses; 4) the severity of endometriosis was variable; 5) studies with unclear pregnancy type could have influenced the overall risk ratio values.

\section{CONCLUSIONS}

Based on the available evidence, this meta-analysis reveals that compared to women without endometriosis, endometriosis women have significantly increased risk of miscarriage, preterm birth, gestational hypertension, placenta previa, cesarean section, and preeclampsia. In the future, research studies should explore the relationship of varying clinical stages of endometriosis on pregnancy outcomes. 
Acknowledgements

None.

Funding

None.

Conflicts of interest

None. 


\section{REFERENCES}

1. Greene AD, Lang SA, Kendziorski JA, et al. Endometriosis: where are we and where are we going? Reproduction. 2016; 152(3): R63-R78, doi: 10.1530/REP-16-0052, indexed in Pubmed: 27165051.

2. Burney RO, Giudice LC, Tamaresis JS, et al. Gene expression analysis of endometrium reveals progesterone resistance and candidate susceptibility genes in women with endometriosis. Endocrinology. 2007; 148(8): 3814-3826, doi: 10.1210/en.2006-1692, indexed in Pubmed: 17510236.

3. Practice Committee of the American Society for Reproductive Medicine. Endometriosis and infertility. Fertil Steril. 2004; 81(5): 1441-1446, doi: 10.1016/j.fertnstert.2004.01.019, indexed in Pubmed: 15136136.

4. Brosens I, Brosens JJ, Fusi L, et al. Risks of adverse pregnancy outcome in endometriosis. Fertil Steril. 2012; 98(1): 30-35, doi: 10.1016/j.fertnstert.2012.02.024, indexed in Pubmed: 22386841.

5. Jenkins S, Olive DL, Haney AF. Endometriosis: pathogenetic implications of the anatomic distribution. Obstet Gynecol. 1986; 67(3): 335-338, indexed in Pubmed: 3945444.

6. Abbas S, Ihle P, Köster I, et al. Prevalence and incidence of diagnosed endometriosis and risk of endometriosis in patients with endometriosis-related symptoms: findings from a statutory health insurance-based cohort in Germany. Eur J Obstet Gynecol Reprod Biol. 2012; 160(1): 79-83, doi: 10.1016/j.ejogrb.2011.09.041, indexed in Pubmed: 22048012. 
7. Parasar P, Ozcan P, Terry KL. Endometriosis: epidemiology, diagnosis and clinical management. Curr Obstet Gynecol Rep. 2017; 6(1): 34-41, doi: 10.1007/s13669-0170187-1, indexed in Pubmed: 29276652.

8. Sampson JA, et al. Metastatic or embolic endometriosis, due to the menstrual dissemination of endometrial tissue into the venous circulation. Am J Pathol. 1927; 3(2): 93-110.43, indexed in Pubmed: 19969738.

9. Laganà AS, Vitale SG, Salmeri FM, et al. Unus pro omnibus, omnes pro uno: A novel, evidence-based, unifying theory for the pathogenesis of endometriosis. Med Hypotheses. 2017; 103: 10-20, doi: 10.1016/j.mehy.2017.03.032, indexed in Pubmed: $\underline{28571791 .}$.

10. Vitale SG, Capriglione S, Peterlunger I, et al. The role of oxidative stress and membrane transport systems during endometriosis: A fresh look at a busy corner. Oxid Med Cell Longev. 2018; 2018: 7924021, doi: 10.1155/2018/7924021, indexed in Pubmed: 29743986.

11. Vercellini P, Viganò P, Somigliana E, et al. Endometriosis: pathogenesis and treatment. Nat Rev Endocrinol. 2014; 10(5): 261-275, doi: 10.1038/nrendo.2013.255, indexed in Pubmed: 24366116.

12. Vitale SG, La Rosa VL, Rapisarda AM, et al. Impact of endometriosis on quality of life and psychological well-being. J Psychosom Obstet Gynaecol. 2017; 38(4): 317319, doi: 10.1080/0167482X.2016.1244185, indexed in Pubmed: 27750472.

13. Aris A. A 12-year cohort study on adverse pregnancy outcomes in Eastern Townships of Canada: impact of endometriosis. Gynecol Endocrinol. 2014; 30(1): 34-37, doi: 10.3109/09513590.2013.848425, indexed in Pubmed: 24134807. 
14. Benaglia L, Bermejo A, Somigliana E, et al. Pregnancy outcome in women with endometriomas achieving pregnancy through IVF. Hum Reprod. 2012; 27(6): 16631667, doi: 10.1093/humrep/des054, indexed in Pubmed: 22447627.

15. Benaglia L, Candotti G, Papaleo E, et al. Pregnancy outcome in women with endometriosis achieving pregnancy with IVF. Hum Reprod. 2016; 31(12): 27302736, doi: 10.1093/humrep/dew210, indexed in Pubmed: 27664955.

16. Bourdon M, Raad J, Dahan Y, et al. Endometriosis and ART: A prior history of surgery for OMA is associated with a poor ovarian response to hyperstimulation. PLoS One. 2018; 13(8): e0202399, doi: 10.1371/journal.pone.0202399, indexed in Pubmed: $\underline{30125306}$.

17. Chen I, Shen M, Singh SS, et al. The association between surgically-diagnosed endometriosis and adverse pregnancy outcomes. J Minim Invasive Gynecol. 2015; 22(6S): S72-S73, doi: 10.1016/j.jmig.2015.08.193, indexed in Pubmed: 27679323.

18. Conti N, Cevenini G, Vannuccini S, et al. Women with endometriosis at first pregnancy have an increased risk of adverse obstetric outcome. J Matern Fetal Neonatal Med. 2015; 28(15): 1795-1798, doi: 10.3109/14767058.2014.968843, indexed in Pubmed: 25262994.

19. Exacoustos C, Lauriola I, Lazzeri L, et al. Complications during pregnancy and delivery in women with untreated rectovaginal deep infiltrating endometriosis. Fertil Steril. 2016; 106(5): 1129-1135.e1, doi: 10.1016/j.fertnstert.2016.06.024, indexed in Pubmed: 27445198.

20. FitzSimmons J, Stahl R, Gocial B, et al. Spontaneous abortion and endometriosis. Fertil Steril. 1987; 47(4): 696-698, doi: 10.1016/s0015-0282(16)59124-9, indexed in Pubmed: $\underline{3569548}$. 
21. Glavind MT, Forman A, Arendt LH, et al. Endometriosis and pregnancy complications: a Danish cohort study. Fertil Steril. 2017; 107(1): 160-166, doi: 10.1016/i.fertnstert.2016.09.020, indexed in Pubmed: 27743699.

22. González-Comadran M, Schwarze JE, Zegers-Hochschild F, et al. The impact of endometriosis on the outcome of Assisted Reproductive Technology. Reprod Biol Endocrinol. 2017; 15(1): 8, doi: 10.1186/s12958-016-0217-2, indexed in Pubmed: $\underline{28118836}$.

23. Harada T, Taniguchi F, Onishi K, et al. Japan Environment \& Children’s Study Group. Obstetrical complications in women with endometriosis: A cohort study in Japan. PLoS One. 2016; 11(12): e0168476, doi: 10.1371/journal.pone.0168476, indexed in Pubmed: 28005934.

24. Hjordt Hansen MV, Dalsgaard T, Hartwell D, et al. Reproductive prognosis in endometriosis. A national cohort study. Acta Obstet Gynecol Scand. 2014; 93(5): 483489, doi: 10.1111/aogs.12373, indexed in Pubmed: 24617701.

25. Jacques M, Freour T, Barriere P, et al. Adverse pregnancy and neo-natal outcomes after assisted reproductive treatment in patients with pelvic endometriosis: a casecontrol study. Reprod Biomed Online. 2016; 32(6): 626-634, doi: 10.1016/j.rbmo.2016.03.005, indexed in Pubmed: 27068240.

26. Kortelahti M, Anttila MA, Hippeläinen MI, et al. Obstetric outcome in women with endometriosis--a matched case-control study. Gynecol Obstet Invest. 2003; 56(4): 207-212, doi: 10.1159/000074815, indexed in Pubmed: 14614250.

27. Kuivasaari-Pirinen P, Raatikainen K, Hippeläinen M, et al. Adverse Outcomes of IVF/ICSI Pregnancies Vary Depending on Aetiology of Infertility. ISRN Obstet Gynecol. 2012; 2012: 451915, doi: 10.5402/2012/451915, indexed in Pubmed: $\underline{22570795}$. 
28. Li H, Zhu HL, Chang XH, et al. Effects of previous laparoscopic surgical diagnosis of endometriosis on pregnancy outcomes. Chin Med J (Engl). 2017; 130(4): 428-433, doi: 10.4103/0366-6999.199840, indexed in Pubmed: 28218216.

29. Lin H, Leng JH, Liu JT, et al. Obstetric outcomes in Chinese women with endometriosis: a retrospective cohort study. Chin Med J (Engl). 2015; 128(4): 455458, doi: 10.4103/0366-6999.151077, indexed in Pubmed: 25673445.

30. Mannini L, Sorbi F, Noci I, et al. New adverse obstetrics outcomes associated with endometriosis: a retrospective cohort study. Arch Gynecol Obstet. 2017; 295(1): 141151, doi: 10.1007/s00404-016-4222-7, indexed in Pubmed: 27770245.

31. Matorras R, Rodríguez F, Gutierrez de Terán G, et al. Endometriosis and spontaneous abortion rate: a cohort study in infertile women. Eur J Obstet Gynecol Reprod Biol. 1998; 77(1): 101-105, doi: 10.1016/s0301-2115(97)00181-4, indexed in Pubmed: $\underline{9550209}$.

32. Mekaru K, Masamoto H, Sugiyama H, et al. Endometriosis and pregnancy outcome: are pregnancies complicated by endometriosis a high-risk group? Eur J Obstet Gynecol Reprod Biol. 2014; 172: 36-39, doi: 10.1016/j.ejogrb.2013.10.024, indexed in Pubmed: 24268981.

33. Nirgianakis K, Gasparri ML, Radan AP, et al. Obstetric complications after laparoscopic excision of posterior deep infiltrating endometriosis: a case-control study. Fertil Steril. 2018; 110(3): 459-466, doi: 10.1016/j.fertnstert.2018.04.036, indexed in Pubmed: $\underline{30098698 .}$.

34. Pittaway DE, Vernon C, Fayez JA. Spontaneous abortions in women with endometriosis. Fertil Steril. 1988; 50(5): 711-715, doi: 10.1016/s00150282(16)60303-5, indexed in Pubmed: $\underline{3181482 .}$ 
35. Safdarian L, Ghalandarpoor Attar SN, Aleyasin A, et al. Investigation of antimullerian hormone (AMH) level and ovarian response in infertile women with endometriosis in IVF cycles. Int J Reprod Biomed. 2018; 16(11): 719-722, indexed in Pubmed: $\underline{30775688}$.

36. Saraswat L, Ayansina DT, Cooper KG, et al. Pregnancy outcomes in women with endometriosis: a national record linkage study. BJOG. 2017; 124(3): 444-452, doi: 10.1111/1471-0528.13920, indexed in Pubmed: 26887349.

37. Stephansson O, Kieler H, Granath F, et al. Endometriosis, assisted reproduction technology, and risk of adverse pregnancy outcome. Hum Reprod. 2009; 24(9): 23412347, doi: 10.1093/humrep/dep186, indexed in Pubmed: 19439428.

38. Stern JE, Liu CL, Hwang SS, et al. Adverse pregnancy and birth outcomes associated with underlying diagnosis with and without assisted reproductive technology treatment. Fertil Steril. 2015; 103(6): 1438-1445, doi: 10.1016/j.fertnstert.2015.02.027, indexed in Pubmed: 25813277.

39. Yang $\mathrm{P}$, Wang $\mathrm{Y}, \mathrm{Wu} \mathrm{Z}$, et al. Risk of miscarriage in women with endometriosis undergoing IVF fresh cycles: a retrospective cohort study. Reprod Biol Endocrinol. 2019; 17(1): 21, doi: 10.1186/s12958-019-0463-1, indexed in Pubmed: 30755216.

40. Lalani S, Choudhry AJ, Firth B, et al. Endometriosis and adverse maternal, fetal and neonatal outcomes, a systematic review and meta-analysis. Hum Reprod. 2018; 33(10): 1854-1865, doi: 10.1093/humrep/dey269, indexed in Pubmed: 30239732.

41. Zullo F, Spagnolo E, Saccone G, et al. Endometriosis and obstetrics complications: a systematic review and meta-analysis. Fertil Steril. 2017; 108(4): 667-672.e5, doi: 10.1016/j.fertnstert.2017.07.019, indexed in Pubmed: 28874260. 
42. Pan ML, Chen LR, Tsao HM, et al. Risk of gestational hypertension-preeclampsia in women with preceding endometriosis: A nationwide population-based study. PLoS One. 2017; 12(7): e0181261, doi: 10.1371/journal.pone.0181261, indexed in Pubmed: $\underline{28715497 .}$.

43. Pérez-López FR, Calvo-Latorre J, Alonso-Ventura V, et al. Health Outcomes, Systematic Analyses (HOUSSAY) Project. Systematic review and meta-analysis regarding the association of endometriosis and preeclampsia in women conceiving spontaneously or through assisted reproductive technology. Pregnancy Hypertens. 2018; 14: 213-221, doi: 10.1016/j.preghy.2018.01.003, indexed in Pubmed: 29934014.

44. Gasparri ML, Nirgianakis K, Taghavi K, et al. Placenta previa and placental abruption after assisted reproductive technology in patients with endometriosis: a systematic review and meta-analysis. Arch Gynecol Obstet. 2018; 298(1): 27-34, doi: 10.1007/s00404-018-4765-x, indexed in Pubmed: 29602980.

45. Laganà AS, Vitale SG, Granese R, et al. Clinical dynamics of Dienogest for the treatment of endometriosis: from bench to bedside. Expert Opin Drug Metab Toxicol. 2017; 13(6): 593-596, doi: 10.1080/17425255.2017.1297421, indexed in Pubmed: $\underline{28537213}$.

46. Raffaelli R, Garzon S, Baggio S, et al. Mesenteric vascular and nerve sparing surgery in laparoscopic segmental intestinal resection for deep infiltrating endometriosis. Eur J Obstet Gynecol Reprod Biol. 2018; 231: 214-219, doi:

10.1016/j.ejogrb.2018.10.057, indexed in Pubmed: $\underline{30415128 .}$.

47. Laganà AS, Vitale SG, Trovato MA, et al. Full-thickness excision versus shaving by laparoscopy for intestinal deep infiltrating endometriosis: rationale and potential 
treatment options. Biomed Res Int. 2016; 2016: 3617179, doi:

10.1155/2016/3617179, indexed in Pubmed: 27579309. 
Figure 1. Flow diagram of the literature search and selection process

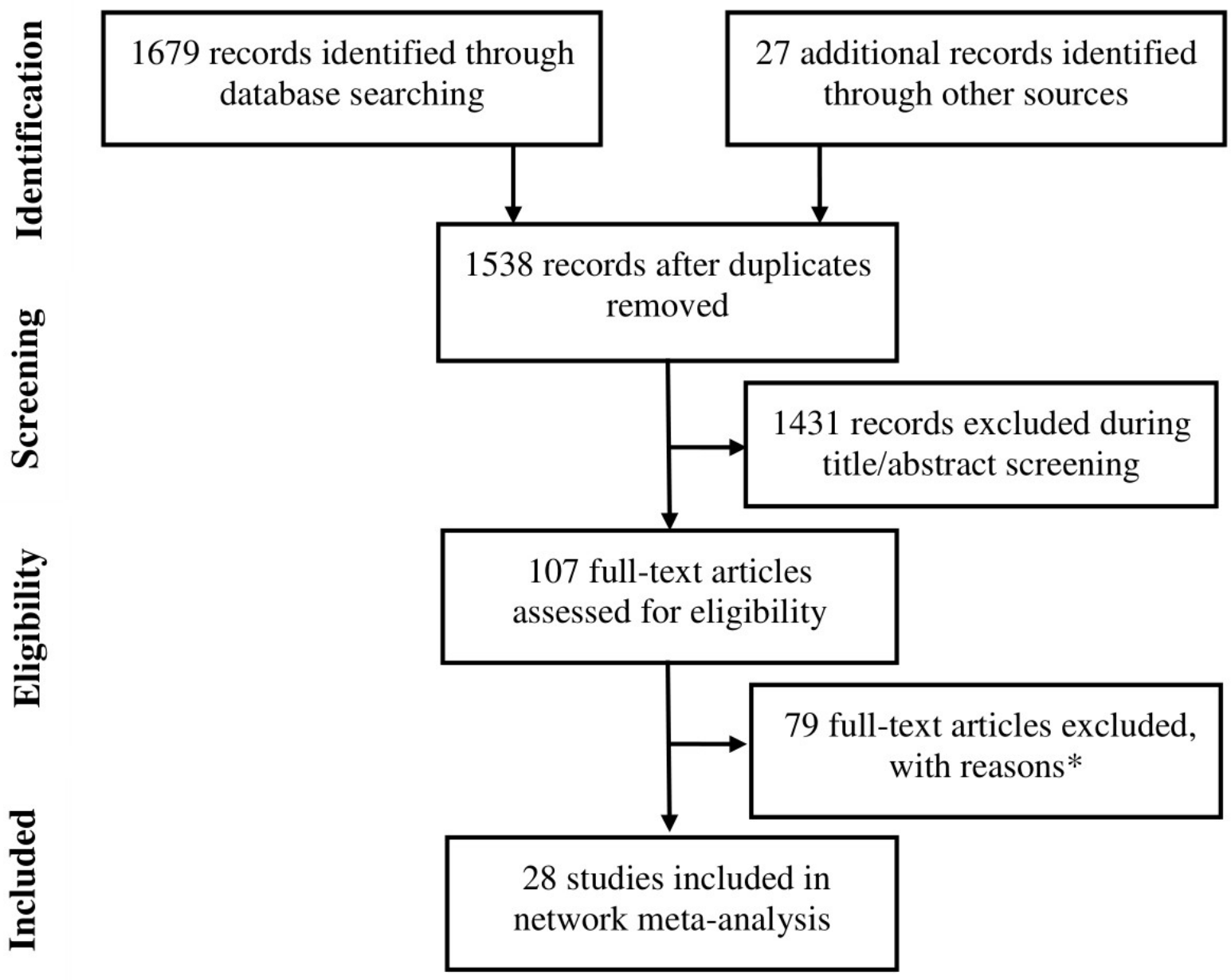

Figure 2. Forest plot for the risk of preterm birth 


\begin{tabular}{|c|c|c|}
\hline $\begin{array}{l}\text { Study } \\
\text { ID }\end{array}$ & RR $(95 \% \mathrm{CI})$ & $\begin{array}{l}\% \\
\text { Weight }\end{array}$ \\
\hline ART vs ART & & \\
\hline Jack FitzSimmons 1987 & $0.86(0.24,3.05)$ & 1.37 \\
\hline Roberto Matorras 1988 & $1.30(0.59,2.89)$ & 2.76 \\
\hline Olof Stephansson 2009 & $1.36(1.28,1.45)$ & 8.25 \\
\hline Paula Kuivasaari-Pirinen 2012 & $2.92(1.61,5.27)$ & 3.95 \\
\hline Laura Benaglia 2012 & $0.47(0.17,1.34)$ & 1.88 \\
\hline Keiko Mekaru 2014 & $0.90(0.21,3.79)$ & 1.10 \\
\hline Judy E Stern 2015 a & $2.93(2.41,3.55)$ & 7.47 \\
\hline Laura Benaglia 2016 & $1.00(0.63,1.58)$ & 5.03 \\
\hline Subtotal (I-squared $=89.8 \%, p=0.000)$ & $1.42(0.94,2.16)$ & 31.81 \\
\hline unclear & & \\
\hline Donald E. Pittaway 1988 & $0.75(0.31,1.81)$ & 2.40 \\
\hline Nathelie Conti 2015 a & $2.03(1.45,2.83)$ & 6.18 \\
\hline Nathelie Conti 2015 b & $0.94(0.46,1.91)$ & 3.19 \\
\hline L Saraswat 2016 & $1.31(1.14,1.51)$ & 7.85 \\
\hline Konstantinos Nirgianakis 2018 & $1.85(0.80,4.24)$ & 2.61 \\
\hline Subtotal $(\mathrm{I}$-squared $=56.0 \%, \mathrm{p}=0.059)$ & $1.40(1.03,1.90)$ & 22.23 \\
\hline spontaneous or ART vs spontaneous or ART & & \\
\hline Aziz Aris 2014 & $1.13(0.92,1.39)$ & 7.35 \\
\hline Caterina Exacoustos 2016 & $5.01(2.68,9.36)$ & 3.72 \\
\hline Luca Mannini 2017 & $2.75(1.79,4.23)$ & 5.26 \\
\hline Maria Tølbøll Glavind 2017 & $1.68(1.41,1.99)$ & 7.64 \\
\hline Konstantinos Nirgianakis 2018 & $1.85(0.80,4.24)$ & 2.61 \\
\hline Innie Chen 2018 & $1.13(0.88,1.43)$ & 7.05 \\
\hline Hui Li 2017 & $1.60(0.64,3.98)$ & 2.29 \\
\hline Subtotal $(\mathrm{I}$-squared $=83.5 \%, \mathrm{p}=0.000)$ & $1.78(1.29,2.45)$ & 35.91 \\
\hline & & \\
\hline pregnancies naturally VS pregnancies naturally & & \\
\hline Hong Lin 2015 & $2.22(1.03,4.78)$ & 2.91 \\
\hline Judy E Stem 2015 b & $1.57(1.25,1.98)$ & 7.14 \\
\hline Subtotal (I-squared $=0.0 \%, p=0.394)$ & $1.62(1.30,2.02)$ & 10.05 \\
\hline Overall $(\mathrm{I}-$ squared $=82.0 \%, \mathrm{p}=0.000)$ & $1.59(1.35,1.87)$ & 100.00 \\
\hline NOTE: Weights are from random effects analysis & & \\
\hline 1 & & \\
\hline
\end{tabular}

Figure 3. Forest plot for the risk of miscarriage 


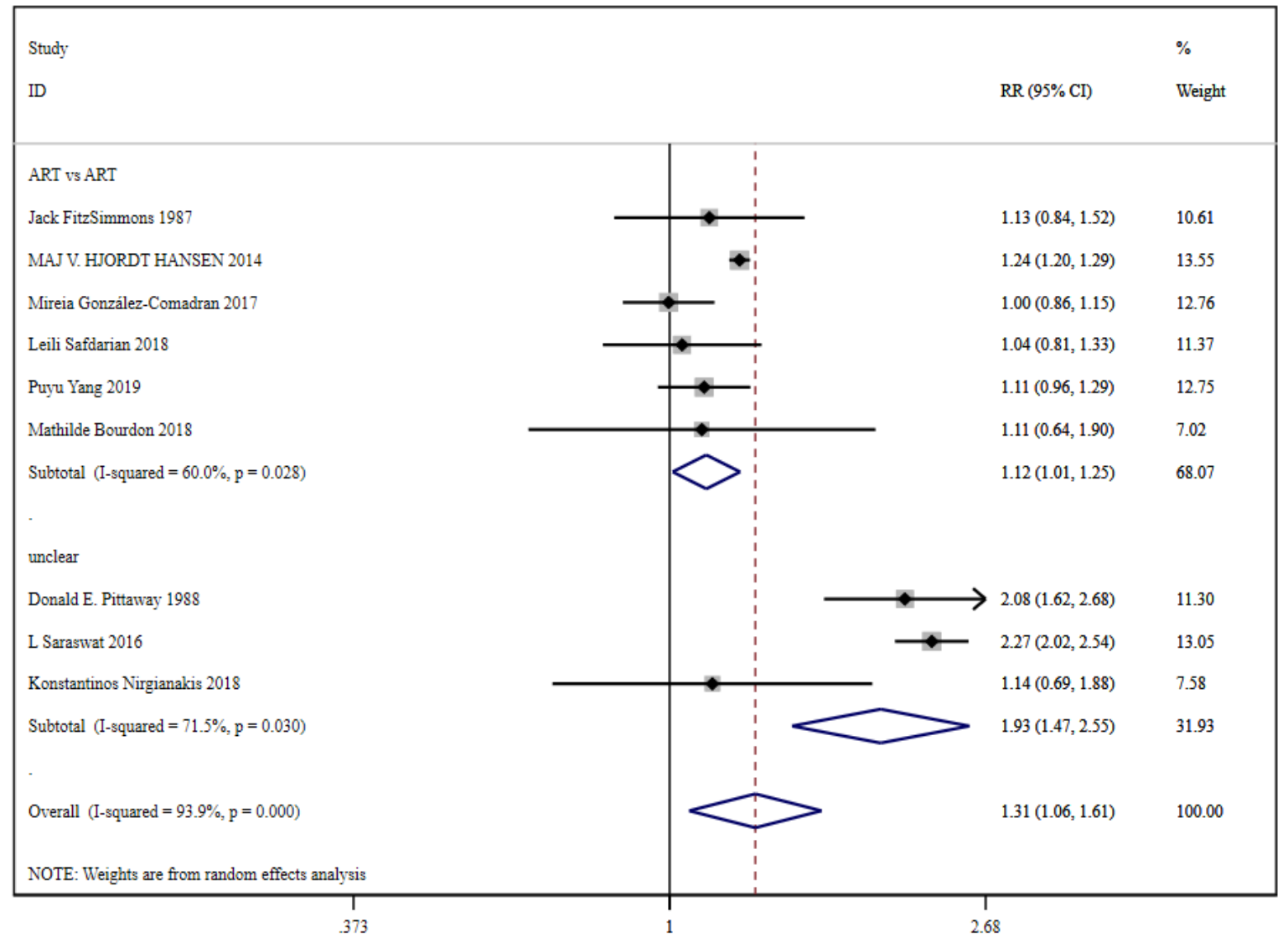

Figure 4. Forest plot for the risk of placenta previa 


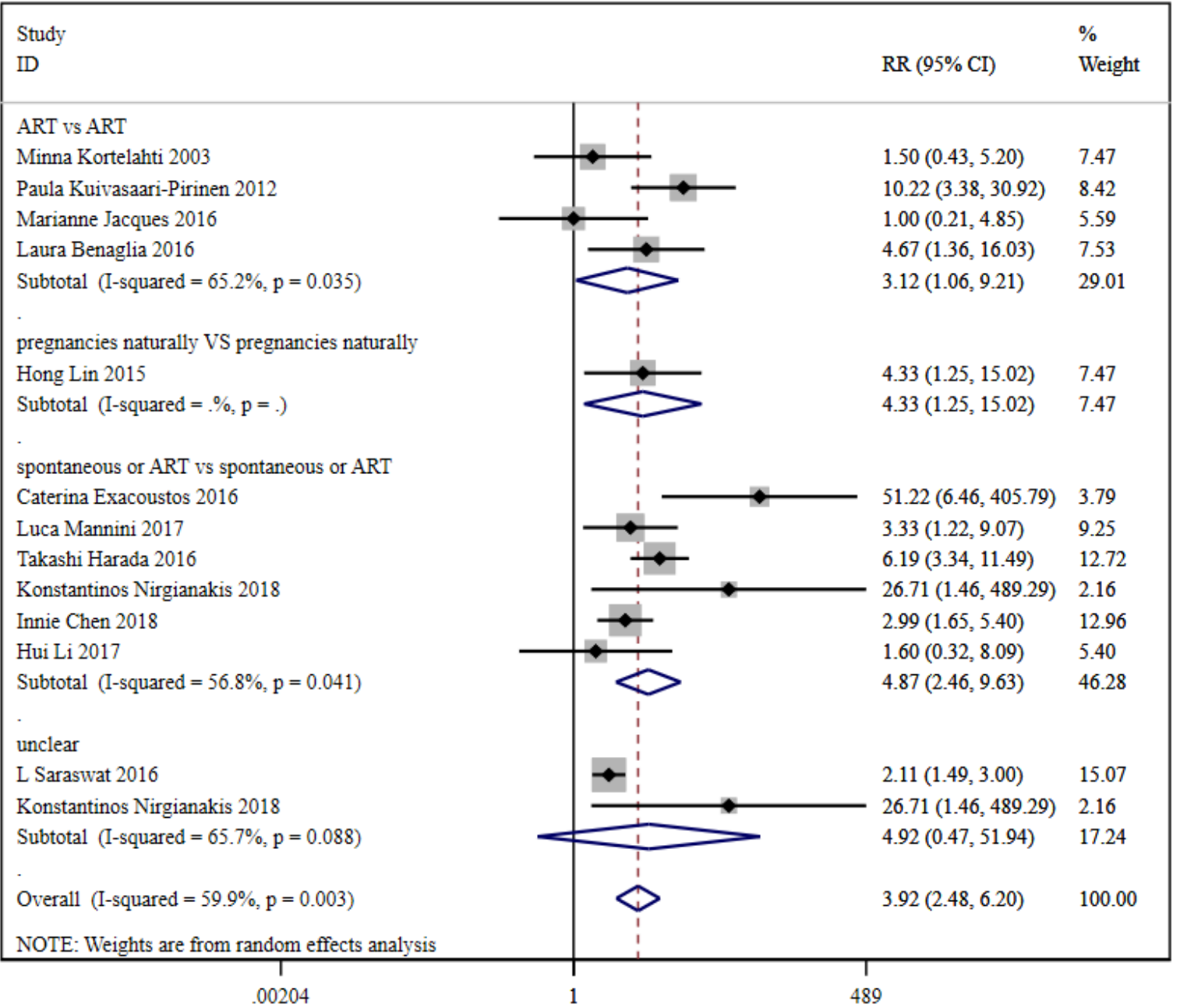

Table 1. The basic characteristics description of included studies

\begin{tabular}{|l|l|l|l|l|l|l|l|}
\hline \multirow{2}{*}{ Ref } & \multicolumn{2}{|c|}{ Study } & \multicolumn{2}{c|}{ No. of patients } & \multicolumn{2}{c|}{ Age } & \multicolumn{3}{c|}{ Pregnancy method } \\
\cline { 3 - 8 } & & EN & \multicolumn{1}{c|}{ C } & EN & \multicolumn{1}{c|}{ C } & \multicolumn{1}{c|}{ EN } & \multicolumn{1}{c|}{ C } \\
\hline 13 & Aris 2014 & 784 & 30284 & - & - & SPONT/ART & SPONT/ART \\
\hline 14 & Benaglia 2012 & 61 & 130 & 35.6 & 36.1 & IVF & IVF \\
\hline 15 & Benaglia 2016 & 239 & 239 & 35.5 & 35.5 & IVF & IVF \\
\hline 16 & Bourdon 2018 & 201 & 402 & 33.7 & 33.7 & ART & ART \\
\hline 17 & Chen 2018 & 469 & 51733 & 32.25 & 30.45 & SPONT/ART & SPONT/ART \\
\hline 18 & Conti 2015 & 219 & 1331 & - & - & - & - \\
\hline 19 & Exacoustos 2016 & 41 & 300 & - & - & SPONT/ART & SPONT/ART \\
\hline
\end{tabular}




\begin{tabular}{|c|c|c|c|c|c|c|c|}
\hline 20 & FitzSimmons 1987 & 52 & 134 & 30.3 & 30.1 & IVF & IVF \\
\hline 21 & Glavind 2017 & 1719 & 81074 & - & - & SPONT/ART & SPONT/ART \\
\hline 22 & $\begin{array}{l}\text { Gonzalez-Comadran } \\
2017\end{array}$ & 3583 & 18833 & 34.83 & 34.61 & IVF & IVF \\
\hline 23 & Harada 2016 & 330 & 8856 & - & - & SPONT/ART & SPONT/ART \\
\hline 24 & Hjordt Hansen 2014 & 24667 & 98668 & - & - & ART & ART \\
\hline 25 & Jacques 2016 & 113 & 113 & 32.4 & 31.4 & ART & ART \\
\hline 26 & Kortelahti 2003 & 137 & 137 & - & - & IVF & IVF \\
\hline 27 & $\begin{array}{l}\text { Kuivasaari-Pirinen } \\
2012\end{array}$ & 49 & 26870 & - & - & IVF/ICSI & IVF/ICSI \\
\hline 28 & Li 2017 & 75 & 300 & 32.8 & 30.1 & SPONT/ART & SPONT/ART \\
\hline 29 & Lin 2015 & 249 & 249 & 32.8 & 30.6 & $\begin{array}{l}\text { Nulliparous / } \\
\text { NP }\end{array}$ & $\begin{array}{l}\text { nulliparous } \\
\text { /NP }\end{array}$ \\
\hline 30 & Mannini 2017 & 262 & 524 & 36.89 & 36.88 & SPONT/ART & SPONT/ART \\
\hline 31 & Matorras 1988 & 174 & 174 & 29.49 & 29.58 & IVF & IVF \\
\hline 32 & Mekaru 2014 & 40 & 48 & - & - & IVF/ET & IVF/ET \\
\hline 33 & Nirgianakis 2018 & 62 & 186 & 33.7 & 33.8 & SPONT/ART & SPONT/ART \\
\hline 34 & Pittaway 1988 & 100 & 250 & - & - & - & - \\
\hline 35 & Safdarian 2018 & 32 & 32 & 31.37 & 31.28 & IVF & IVF \\
\hline 36 & Saraswat 2016 & 4232 & 6707 & 30.5 & 27.2 & - & - \\
\hline 37 & Stephansson 2009 & 13090 & 1429585 & - & - & ART & ART \\
\hline 38 & Stern 2015 & 996 & 297987 & 35.2 & 29.7 & ART/ NP & ART \\
\hline 39 & Yang 2019 & 1006 & 2012 & 33.04 & 32.83 & IVF & IVF \\
\hline
\end{tabular}

ART — assisted reproductive technology; C — control; ET — embryo transfer; ICSI — Intracytoplasmic sperm injection; IVF — in vitro fertilization; NE - endometriosis group; $\mathrm{NP}$ — natural pregnancy; SPONT — spontaneous; T — treatment 